\title{
Studies on the Induction and Turnover of Citrate-oxidizing Capacity in Klebsiella aerogenes Using Chemostat Culture
}

\author{
By R. E. ASHBY* AND D. E. F. HARRISON $\dagger$ \\ Biological Laboratory, University of Kent, Canterbury, Kent CT2 7NJ
}

(Received 3 December 1979; revised 1 April 1980)

\begin{abstract}
Steady-state chemostat cultures of Klebsiella aerogenes growing on a carbon-limited medium were challenged with pulses of carbon sources, and the resultant changes in dissolved oxygen tension were shown to reflect changes in respiration rate. These changes were used to study the kinetics of induction of citrate-oxidizing capacity, which is most probably limited by citrate permease, and the return to the preinduced state. Previously unexposed cells showed a lag phase, the duration of which decreased with increasing growth rate, with a minimum of $10 \mathrm{~min}$, followed by an induction phase of linear increase of citrate oxidation rate which continued as long as citrate was present. The rate of increase in activity, which can be equated to the rate of induction of citrate permease, was independent of citrate concentration but increased with growth rate. Previously exposed cells showed no lag and some residual activity before further induction. The kinetics of return to the preinduced state were unusual in that activity was short-lived with a half-life of 16 to 23 min while the lag took over $8 \mathrm{~h}$ to re-establish. The rate of decay of activity decreased with increasing growth rate.
\end{abstract}

\section{INTRODUCTION}

The development of reliable dissolved oxygen probes (Mackereth, 1964; Borkowski \& Johnson, 1967) has allowed the study of the effects of dissolved oxygen tension (DOT) on microbial metabolism (Harrison, 1976). Conversely, metabolic effects can change DOT and metabolism can be studied by following these changes; thus, Harrison \& Maitra (1969) studied the effects on DOT of pulse additions of substrates to steady-state chemostat cultures. In the work reported here, the technique was developed to investigate the kinetics of induction and turnover of citrate-oxidizing capacity in Klebsiella aerogenes. The method relies on an equilibrium established at steady-state between the respiration rate and the oxygen transfer rate to the culture which determines the DOT. The oxygen transfer rate $(N)$ is proportional to $K_{\mathrm{L}} a$, the gas transfer coefficient, and $\triangle \mathrm{DOT}$, the difference between the saturation DOT and the observed DOT: $N=K_{\mathrm{L}} a . \Delta \mathrm{DOT}$.

If $K_{\mathrm{L}} a$ is held constant, $\triangle \mathrm{DOT}$ is proportional to the respiration rate, and so changes in respiration rates of steady-state cultures may be monitored by following $\Delta$ DOT. In practice, $K_{\mathrm{L}} a$ is adjusted before the experiment so that it is small enough to provide a measurable $\triangle \mathrm{DOT}$ for the respiratory changes examined, but large enough to prevent DOT from dropping to a level at which it would affect metabolism, i.e. approximately $1.3 \mathrm{kPa}$ (Harrison, 1976). $K_{\mathrm{L}} a$ may be adjusted by altering the partial pressure of oxygen in the input gas or by changing the stirring and aeration rates. In the latter case, it is necessary to recalibrate the oxygen probe for each new set of conditions to allow for changes in gas hold-up (Votruba et al., 1977) and pressure.

The organism we have used is Klebsiella aerogenes, whose behaviour with respect to oxygen has been closely studied (Harrison \& Pirt, 1967; Harrison \& Loveless, $1971 a, b$; Páca \& Vratislav, 1977).

$$
\dagger \text { Present address: Pfizer Central Research, Sandwich, Kent. }
$$




\section{METHODS}

Organism. Klebsiella aerogenes Type 1 was maintained by subculture in nutrient broth (Oxoid).

Continuous culture. The medium used, which gave carbon-limited growth, contained $\left(\mathrm{g}^{-1}\right)$ : glucose, $4.0 ; \mathrm{Na}_{2} \mathrm{HPO}_{4}, 3.0 ; \mathrm{KH}_{2} \mathrm{PO}_{4}, 3.0 ;\left(\mathrm{NH}_{4}\right)_{2} \mathrm{SO}_{4}, 3.0 ; \mathrm{MgSO}_{4} .7 \mathrm{H}_{2} \mathrm{O}, 0.2 ; \mathrm{FeCl}_{3} .6 \mathrm{H}_{2} \mathrm{O}, 0.0167$; and trace elements $\left(\mathrm{mg} \mathrm{l}^{-1}\right): \mathrm{CaCl}_{2} . \mathrm{H}_{2} \mathrm{O}, 0 \cdot 66 ; \mathrm{ZnSO}_{4} .7 \mathrm{H}_{2} \mathrm{O}, 0 \cdot 18 ; \mathrm{CuSO}_{4} .5 \mathrm{H}_{2} \mathrm{O}, 0 \cdot 16 ; \mathrm{MnSO}_{4} \cdot 4 \mathrm{H}_{2} \mathrm{O}, 0 \cdot 15 ; \mathrm{CoCl}_{2}$. $6 \mathrm{H}_{2} \mathrm{O}, 0 \cdot 18 ; \mathrm{H}_{3} \mathrm{BO}_{3}, 0 \cdot 10 ; \mathrm{Na}_{2} \mathrm{MoO}_{4} \cdot 2 \mathrm{H}_{2} \mathrm{O}, 0.3$.

Glucose, $\mathrm{MgSO}_{4}$ and trace elements were prepared at double-strength in 201 batches as component $\mathrm{A}$ and acidified with $10 \mathrm{ml}$ concentrated $\mathrm{HCl}$ before autoclaving at $121^{\circ} \mathrm{C}$ for $50 \mathrm{~min} . \mathrm{Na}_{2} \mathrm{HPO}_{4}, \mathrm{KH}_{2} \mathrm{PO}_{4}$ and $\left(\mathrm{NH}_{4}\right)_{2} \mathrm{SO}_{4}$ were prepared and autoclaved as component $\mathrm{B}$. The two components were pumped separately (Watson-Marlow Flow Inducer) and mixed in the fermentation vessel. $\mathrm{FeCl}_{3}$ was filter-sterilized $(0.22 \mu \mathrm{m}$ pore size) before adding to component $\mathrm{A}$.

Cultures were grown in a Biotec FL103 fermentation vessel with a working volume of 2.561. The pH was measured using a combination glass/calomel reference electrode (Radiometer, Copenhagen) connected to a 91B pH controller (Electronic Instruments Ltd) and maintained between pH 6.4 and 6.8 by automatic additions of $2 \mathrm{M}-\mathrm{HCl}$ and $2 \mathrm{M}-\mathrm{KOH}$. Dissolved oxygen tension (DOT) was measured with a sterilizable oxygen electrode of the Johnson type (Western Biological Equipment) modified by replacing the standard acetate buffer with one containing $150 \mathrm{~g} \mathrm{~K}_{2} \mathrm{CO}_{3} \mathrm{l}^{-1}$ and $50 \mathrm{~g} \mathrm{KHCO}_{3} \mathrm{l}^{-1}$. The probe was connected to a $5 \mathrm{k} \Omega$ variable resistance, and the system was calibrated for each set of stirring and aeration conditions to give an ouput of $10 \mathrm{mV}$ corresponding to saturation DOT. This signal was fed to a multiple range potentiometric chart recorder with zero offset facility (Servoscribe 2s, Smith's Industries) which allowed small variations in signal to be amplified and examined. Steady-state DOT was altered by adjusting the stirring speed, controlled by a thyristor motor controller with tachometer feedback (Shackleton System Drives), and aeration rate, controlled by a type MNAF Flostat (G. A. Platon), to be in the range 8.8 to $13 \mathrm{kPa}$. During experiments, results were discarded if DOT fell below $4.0 \mathrm{kPa}$.

The temperature was maintained at $30^{\circ} \mathrm{C}$. Temperature control using directly controlled (on/off) heating was unsuitable because the small temperature cycle (approximately $\pm 0 \cdot 1{ }^{\circ} \mathrm{C}$ ) was amplified by the temperature sensitivity of the oxygen electrode to give an oscillating DOT trace. Temperature was therefore controlled by circulating water at a few degrees above $30^{\circ} \mathrm{C}$, depending on ambient temperature, from a water bath through a heat exchanger in the vessel. A slow temperature drift of up to $0.4{ }^{\circ} \mathrm{C}$ was experienced but, although this was reflected by a drift in DOT measurements (up to $5 \%$ over $8 \mathrm{~h}$ ), it did not interfere with the measurement of short-term variations.

Analytical methods. Oxygen in the effluent gas was determined by passing the gas via a condenser and filter to a paramagnetic oxygen analyser (Taylor Servomex) where it was compared with the input gas. Carbon dioxide was determined in the same effluent gas using an infrared gas analyser (M.S.A., LIRA).

Steady-state. Samples were taken daily and cells were harvested by centrifugation $(1500 \mathrm{~g}, 20 \mathrm{~min})$ and washed twice in distilled water before being dried for $24 \mathrm{~h}$ at $95^{\circ} \mathrm{C}$ for dry weight measurements. Weekly samples were diluted in quarter-strength Ringer's solution and spread plated on to nutrient agar (Oxoid) followed by incubation at $30^{\circ} \mathrm{C}$ for $7 \mathrm{~d}$ to check the absence of contaminants. Steady-state, as determined by dry weight, DOT and gas analysis, wasusually reached within $24 \mathrm{~h}$ of inoculation or change in dilution rate, but it was maintained for $3 \mathrm{~d}$ before experiments were begun.

Challenge by carbon source pulses. Steady-state cultures were challenged by injecting known volumes of $1 \mathrm{~m}$ solutions into the fermentation vessel. Ionized solutions, e.g. sodium citrate, were adjusted to $\mathrm{pH} 6.5$ before use.

\section{RESULTS}

\section{Challenge by carbon source pulses}

Addition of glucose (final concentration approximately $2 \mathrm{~mm}$ ) to a steady-state carbonlimited culture caused a rapid decrease in DOT to a new value DOT* (Fig. 1a). The time taken for DOT to reach DOT* was less than $2 \mathrm{~min}$, which was within the response time of the oxygen probe, and thus the decrease in DOT on addition of glucose was, for practical purposes, instantaneous.

The difference between saturation DOT and observed DOT, i.e. $\triangle \mathrm{DOT}$, thus increased and this must represent an increase in respiration rate as $K_{\mathrm{L}} a$ was unaltered. After reaching DOT $^{*}$, the DOT returned to the steady-state level forming a curve, the integrated area of which was constant for equal volumes of added glucose and increased in proportion with 


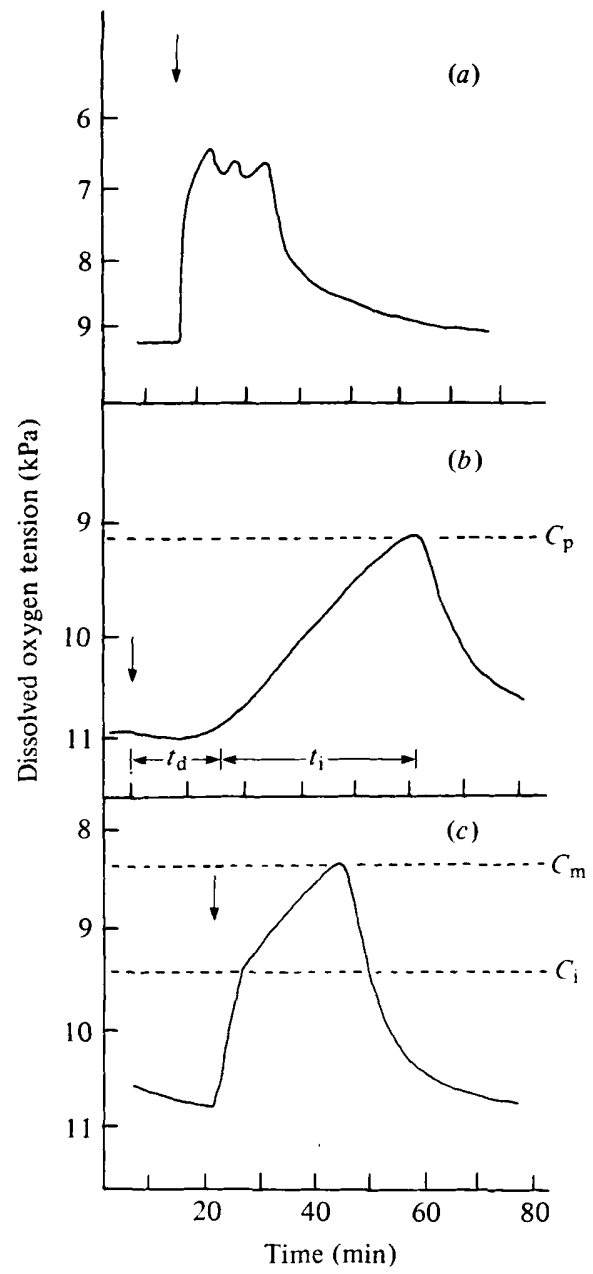

Fig. 1. Effect on DOT of the addition of pulses of carbon substrates to steady-state carbonlimited cultures of $K$. aerogenes grown at a dilution rate of $0 \cdot 175 \mathrm{~h}^{-1}$. (a) Glucose (final concentration $2 \mathrm{mM}$ ) was injected into a culture at the time indicated by the arrow. (b) Sodium citrate at pH 6.5 (final concentration $2 \mathrm{~mm}$ ) was injected into a previously unexposed culture. (c) Sodium citrate at pH 6.5 (final concentration $2 \mathrm{~mm}$ ) was injected into a culture previously exposed to citrate.

increased volumes of added glucose. The return to the steady-state level was marked by two oscillations in DOT (Fig. 1a).

Similar responses were observed when the carbon source added was fructose, mannose, mannitol, glycerol, acetate or pyruvate. Other carbon sources - galactose, sucrose, xylose, succinate, fumarate, malate and glycerol - gave a more gradual decrease in DOT. The corresponding increase in $\triangle \mathrm{DOT}$, slow in comparison with the response time of the probe, must indicate a slowly accelerating respiration rate, i.e. the induction of oxidizing capacity for the substrate. Citrate gave a more complex response consisting of a lag period followed by a slow linear decrease in DOT (Fig. $1 b$ ), which was studied in more detail.

There was no response to the addition of ammonium, phosphate, magnesium or iron, indicating that these were not limiting for respiration.

\section{Challenge by pulses of citrate}

When citrate ( $2 \mathrm{mM}$ ) was added (Fig. $1 b$ ) to a previously unexposed culture, after a lag $\left(t_{\mathrm{d}}\right)$, DOT decreased linearly for a time $\left(t_{\mathrm{i}}\right)$, followed by a return to its original level. Cells 
previously exposed to citrate (Fig. $1 c$ ) showed no detectable lag but an immediate fall in DOT (i.e. within the response time of the probe) to a level $\left(C_{1}\right)$ related to the time elapsed since the previous exposure to citrate $\left(t_{\mathrm{c}}\right)$ and the previous response peak $\left(C_{\mathrm{p}}\right)$. This was followed by a linear decline to a minimum value $\left(C_{\mathrm{m}}\right)$ and then a return to the steady-state level similar to that observed previously. The slope of the linear decline was the same as for the previously unexposed culture. Increasing the amount of citrate added to the culture increased the integrated area of the response curve in a way similar to that shown for glucose. The lag time, however, remained constant, as did the slope of the response.

The slow linear increase in $\triangle D O T$ in Fig. $1(b)$ and in the second part of the response in Fig. $1(c)$ indicates that citrate-oxidizing activity was increasing with zero order kinetics, i.e.:

and

$$
\mathrm{d} c / \mathrm{d} t=-A \bar{x}
$$

$$
A=A_{0}+I t
$$

where $c$ is the concentration of citrate in the culture at time $t\left(\mathrm{~g} \mathrm{l}^{-1}\right), A$ is the citrate-oxidizing activity at time $t$ [g citrate ( $\mathrm{g}$ cells) $)^{-1} \mathrm{~h}^{-1}$ ], $\bar{x}$ is the steady-state biomass $\left(\mathrm{g} \mathrm{l}^{-1}\right), A_{0}$ is the citrate-oxidizing activity at $t_{0}$ [g citrate $\left.(\mathrm{g} \text { cells })^{-1} \mathrm{~h}^{-1}\right], I$ is the rate of increase (induction) of citrate-oxidizing activity [g citrate $\left.(\mathrm{g} \text { cells })^{-1} \mathrm{~h}^{-2}\right]$ and $t$ is the time elapsed since injection of citrate (h).

Injecting more citrate into the culture as soon as the DOT had returned to its original level caused an immediate increase in respiration rate indicating that the fall in respiration rate after DOT reached a minimum was caused by exhaustion of citrate. This was corroborated by the observation that the area under the response curve was proportional to the amount of citrate added.

\section{Effect of continuous addition of citrate}

In some experiments, citrate was added to the feed medium at $10 \%$ of the glucose concentration so that the culture was exposed continuously to citrate while remaining carbon-limited. When such cultures were challenged no lag was observed, but the usual slow linear increase in $\triangle D O T$ occurred. The slope of the response and its integrated area were similar to those for unexposed cultures.

\section{Effect of growth rate on induction lag time}

Growth rate was varied by changing the dilution rate $(D)$ in the range 0.025 to $0.3 \mathrm{~h}^{-1}$, and the lag time $\left(t_{\mathrm{d}}\right)$ was measured from the chart recorder trace. The results are shown in Fig. 2, where the reciprocal of the lag time $\left(1 / t_{\mathrm{d}}\right)$ is plotted against $D$, each point being an average of typically four determinations. The experiment was also conducted at zero growth rate using non-growing cells obtained by switching off the medium feed pump and waiting until steady-state DOT was re-established at saturation DOT. Sensitivity was then increased by switching off the air flow as such cultures showed no oxygen uptake. The non-growing cultures showed no response to pulses of citrate even after $4 \mathrm{~h}$, although they responded immediately and characteristically to glucose. Reciprocal $t_{\mathrm{d}}$ at $D=0$ is therefore regarded as approaching zero.

\section{Effect of growth rate on the rate of induction of citrate-oxidizing capacity}

Although it is possible to estimate the rate of induction of citrate-oxidizing capacity $(I)$ from the slope of the trace of the induction response, this requires estimations of $K_{\mathrm{L}} a$ for each set of stirring and aeration conditions, because the slope is affected by $K_{\mathrm{L}} a$ as well as by the rate of induction. Alternatively, since the amount of citrate utilized $(\Delta c)$ and the steady-state biomass $(\bar{x})$ are known, and since the addition of citrate caused no significant change in $\bar{x}$ from the steady-state value, $I$ can be calculated from the induction time $\left(t_{1}\right)$, defined as the time from when citrate-oxidizing activity was first observed at the end of the 


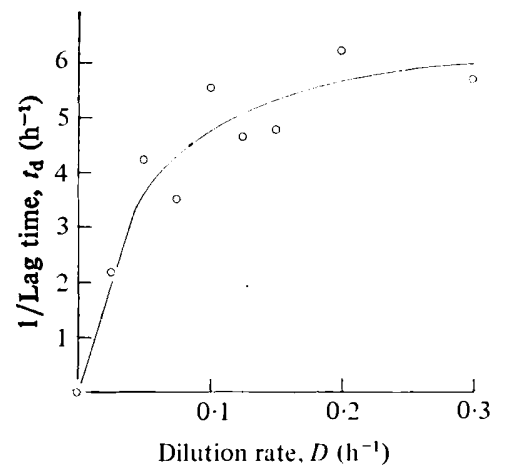

Fig. 2

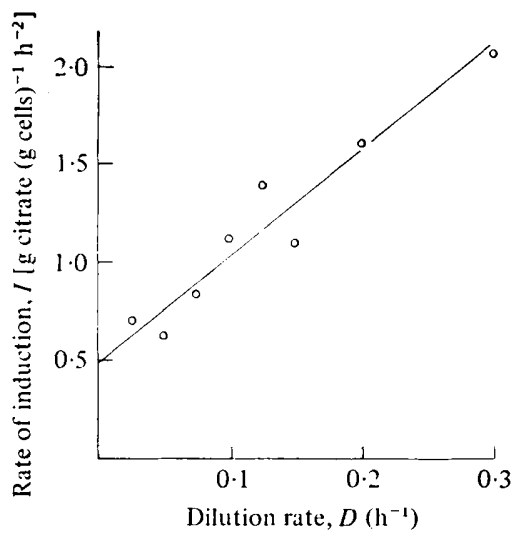

Fig. 3

Fig. 2. Effect of dilution rate on the reciprocal lag time before the response of steady-state cultures of $K$. aerogenes to the addition of pulses of sodium citrate at pH 6.5 (final concentration $2 \mathrm{mM}$ ).

Fig. 3. Effect of dilution rate on the rate of induction of citrate-oxidizing capacity in steady-state cultures of $K$. aerogenes exposed to pulses of sodium citrate at pH 6.5 (final concentration $2 \mathrm{~mm}$ ).

lag period to when activity reached its peak, i.e. the time during which activity increased. Varying $K_{\mathrm{L}} a$ while holding $D$ constant showed that $t_{1}$ was independent of $K_{\mathrm{L}} a$.

From equations 1 and 2:

$$
\mathrm{d} c / \mathrm{d} t=-\left(A_{0}+I t\right) \bar{x}
$$

therefore

$$
c=-\int_{t_{0}}^{t_{1}}\left(A_{0}+I t\right) \bar{x} \mathrm{~d} t
$$

At steady-state, $\bar{x}$ is independent of $t$, so:

$$
c=c_{0}-A_{0} \bar{x} t_{\mathrm{i}}-\frac{1}{2} I \bar{x} t_{\mathrm{i}}^{2}
$$

For a previously unexposed culture, $A_{0}=0$ and, by definition, $\Delta c=c_{0}-c$, therefore

$$
I=\frac{2 \Delta c}{\bar{x}} \cdot \frac{1}{t_{i}^{2}}
$$

Figure 3 shows a plot of $I$ against $D$ demonstrating a linear relationship with higher induction rates at higher growth rates and a positive intercept at $D=0$.

\section{Return to the preinduced state}

It was observed that the response $\left(C_{1}\right)$ of pre-exposed cells to a further citrate challenge was related to the previous response peak $\left(C_{\mathrm{p}}\right)$ but decreased with the time elapsed since that peak $\left(t_{\mathrm{c}}\right)$, see Fig. 1. The value $C_{\mathrm{p}}$ reflects the maximum citrate-oxidizing capacity reached before citrate became exhausted and $C_{i}$ represents the residual citrate-oxidizing capacity at the time of the subsequent challenge. Therefore, the decrease in $C_{i}$ with increasing time between challenges $\left(t_{\mathrm{o}}\right)$ represents the decay of the citrate-oxidizing capacity in the absence of citrate. The values $C_{\mathrm{l}}$ and $C_{\mathrm{p}}$ are affected equally by $K_{\mathrm{L}} a$ and in the plot $C_{\mathrm{l}} / C_{\mathrm{p}}$ against $t_{\mathrm{c}}$ the effects of $K_{\mathrm{L}} a$ cancel and a true decay curve may be obtained. In Fig. 4 a logarithmic plot has been used to demonstrate that this decay is exponential, at a rate approximating in this example to 20 times the dilution rate. Some points on the graph are greater than unity because $C_{1}>C_{\mathrm{p}}$ when $t_{\mathrm{c}}$ is small, that is to say, the induction of citrateoxidizing capacity continues for a short while after the apparent exhaustion of citrate.

Decay rates of citrate-oxidizing capacity at different dilution rates are shown in Fig. 5; 


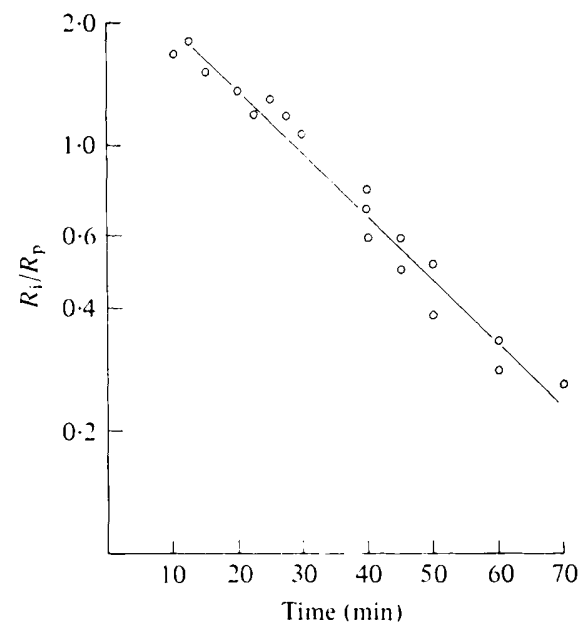

Fig. 4

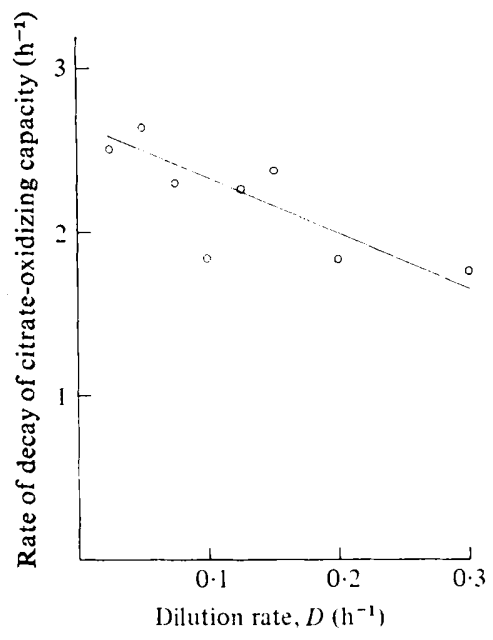

Fig. 5

Fig. 4. Decay of citrate-oxidizing capacity in steady-state cultures of $K$. aerogenes with time elapsed since previous exposure to citrate. $R_{\mathrm{i}} / R_{\mathrm{p}}$ relates the height of the immediate response in $\triangle \mathrm{DOT}$ after addition of citrate to the peak height of the previous response. Time refers to the time elapsed between the previous peak response and the subsequent addition of citrate.

Fig. 5. Effect of dilution rate on the rate of decay of citrate-oxidizing capacity. Decay rates were calculated as in Fig. 4.

a small correction has been made to the decay rates by substracting $D$ to allow for the dilution of induced cells by washout. The decay rate generally declines with increasing dilution rate.

Precise data could not be obtained on the re-establishment of the lag period. Up to $8 \mathrm{~h}$ after a previous exposure to citrate, cells responded to a further challenge without lag. Allowing longer intervening periods showed that lag was re-established gradually, appearing as a small decrease in the initial slope of the early stages of induction. This could not be quantified accurately. The lag was fully re-established after $18 \mathrm{~h}$.

\section{Analysis of fermenter effluent gas}

In some experiments the fermenter effluent gas was analysed for oxygen and carbon dioxide during the induction and decay of citrate-oxidizing capacity. In all cases the fall in DOT was accompanied by an increased oxygen uptake and carbon dioxide production, demonstrating that the increases in $\triangle \mathrm{DOT}$ were caused by increases in respiration rate and not, for example, changes in $K_{\mathrm{L}} a$.

\section{DISCUSSION}

A major advantage of the method of investigating the respiratory activity of continuous cultures described here was the absence of external shocks to metabolism caused by, for example, sampling, centrifugation, washing (Pine, 1970) and temperature changes. The condition of the cells remained constant up to the moment the experiment began and they were at a predetermined growth rate which could be altered to examine its effects. A further advantage, when investigating a system subject to catabolite repression, was that by maintaining the culture carbon-limited catabolite repression was avoided (McGinnis \& Paigen 1969, 1973).

Challenge to a carbon-limited steady-state culture of $K$. aerogenes by the addition of known amounts of carbon source (typically $5 \mathrm{ml}$ of $1 \mathrm{M}$ solution giving a concentration in the culture of approximately $2 \mathrm{~mm}$ ) led in most cases to immediate increases in respiration 
rate, reflected in a proportional increase in $\triangle D O T$. In the case of glucose, the return to steady-state DOT was preceded by two oscillations in accord with the response to glucose pulses reported by Harrison \& Maitra (1969). These presumably represent short bursts of respiration from oxidation of metabolites produced while glucose was in excess (Neijssel $\&$ Tempest, 1975). Citrate gave a different response: a gradually increasing respiration rate after an initial lag. These results correspond with those of Villarreal-Moguel \& RuizHerrera (1969) and Davis (1956) who showed that Aerobacter aerogenes metabolized citrate only after a lag which they related to the induction of a permeability system. The system was located on the membrane, contained a protein moiety, was highly specific and required energy for citrate penetration. Its induction required the synthesis of RNA and protein. They concluded that the limiting step for the utilization of exogenous citrate was the synthesis of this specific permeability system. Guerrero-Caballero \& Ruiz-Herrera (1971) showed that penetration followed Michaelis-Menten type kinetics and concluded that the system was a permease.

On this evidence, it seems reasonable to assume that the citrate-oxidizing capacity can be equated with citrate permease activity. Thus, the increasing respiration rate can be regarded as reflecting an increasing activity of citrate permease at the cell surface. The major component of the lag time was thus the time required before permease appeared at the cell surface, and the slope of the response in Fig. 1(b) reflected the rate of production of permease, which we have termed the induction rate. The immediate response in Fig. $1(c)$ reflected the amount of permease remaining from the previous induction.

In cells previously exposed to citrate, citrate permease was induced without lag on further exposure to citrate, even after $8 \mathrm{~h}$ when no residual pemease activity could be detected. This absence of lag might have been due to the retention of specific mRNA, but the time required for the re-establishment of lag was much longer than estimates of mRNA lifetime (Adesnik \& Levinthal, 1970; Gray \& Midgley, 1970; Cybis \& Weglenski, 1972; Tønnesen \& Friesen, 1973; Lawther \& Cooper, 1975), which suggest a half-life for mRNA of a few minutes. Alternatively, the abolition of lag might reflect the presence of low activities of residual permease on the cell surface which transported sufficient citrate to act as an inducer but gave undetectable rates of oxidation, previously unexposed cells having no permease. The lag would then represent the time required for passive diffusion of citrate into the cells. However, this was not supported by the fact that lag remained constant for different concentrations of added citrate. Possibly the lag represents the induction of a second transport system with greater sensitivity to citrate but a slower rate, and a much slower decay rate. This would then act as a priming system for the main permease.

In cells previously continuously exposed to citrate there was no lag when extra citrate was pulsed in, but no immediate step increase in $\triangle D O T$ occurred. This may indicate that the amount of permease present was precisely matched to the concentration of citrate at steady-state so that excess citrate could not be oxidized before the induction of more permease.

The growth rate was shown to affect the induction lag time, the lag being shorter in faster growing cells. The reason that non-growing cells did not induce citrate permease might have been that the lag became infinitely long, rather than the induction rate became zero.

The induction rate reflected the rate of appearance of the permease activity and was shown to be affected by growth rate. Jacob \& Monod (1961) predicted that a newly induced protein would be produced as a constant proportion of the total cell protein production; this was in accord with the linear relationship between $I$ and $D$ found here. The implication of a positive intercept at $D=0$ was that total cell protein production occurred at zero growth rate, presumably as turnover. This would contribute to the requirement for maintenance energy (Marr et al., 1963; Pirt, 1975). Total cell protein turnover could not be measured directly using our system, but could be estimated from an equation derived from Fig. 3: 


\section{Protein production $=$ Constant $\times(D+0.088)$}

where 0.088 has the dimensions $\mathrm{h}^{-1}$. A turnover rate of $0.088 \mathrm{~h}^{-1}$ was comparable with turnover rates for total biomass (i.e. the specific maintenance rate, see Pirt, 1975) in Escherichia coli of 0.018 to $0.028 \mathrm{~h}^{-1}$ (Marr et al., 1963) and $0.06 \mathrm{~h}^{-1}$ (Pirt, 1975), and protein turnover in non-growing cells of $0.06 \mathrm{~h}^{-1}$ (Mandlestam, 1960), but was rather higher than the value of $0.006 \mathrm{~h}^{-1}$ given for protein turnover in growing cells (Mandlestam, 1960).

General protein turnover rates have usually been found to be low (Mandlestam, 1960; Pine, 1972; Fensom \& Pirt, 1975), and this has led to the expectation that specific enzymes would be lost by dilution by the growing culture, rather than by turnover. There has indeed been evidence to support this hypothesis (Cybis \& Weglenski, 1972; Lawther \& Cooper, 1975). Here, however, we have reported loss of permease activity at rates of 1.8 to $2.6 \mathrm{~h}^{-1}$, giving half-lives of 16 to $23 \mathrm{~min}$. This was an order of magnitude greater than the dilution rates and very much faster than general protein turnover rates. It has been suggested that specific rates for permeases might be faster (Pine, 1965) and, in particular, Robertson \& Halvorson (1957) found that maltose permease decayed more rapidly in yeast than other enzymes required to ferment maltose, leading after $3 \mathrm{~h}$ to crypticity. Similarly, $\beta$-galactoside permease was found to be much less stable than $\beta$-galactoside in $E$. coli (Koch, 1963).

Permease decay rates were found to be slower at higher growth rates. There are few comparable data in the literature because the disruptions caused by other experimental procedures make this relationship difficult to study. Pirt \& Righelato (1967) found that the decay of penicillin production rate in Penicillium chrysogenum showed an inverse relationship with the growth rate before harvesting. If this were to apply to most enzyme systems then the fraction maintenance energy due to total protein turnover would decrease with growth rate rather than remaining constant (Pirt, 1975).

We thank Mr I. S. Allen for his technical assistance.

\section{REFERENCES}

AdesniK, M. \& LeVINTHAL, C. (1970). The synthesis and degradation of lactose operon messenger RNA in E. coli. Cold Spring Harbor Symposia on Quantitative Biclogy 35, 451-459.

BoRKowski, J.D. \& Johnson, M.J. (1967). Longlived steam-sterilizable probes for dissolved oxygen measurement. Biotechnology and Bioengineering 9, 635-639.

Cybis, J. \& Weglenski, P. (1972). Arginase induction in Aspergillus nidulans. The appearance and decay of the coding capacity of messenger. European Journal of Biochemistry 30, 262-268.

Davis, B. D. (1956). Relations between enzymes and permeability (membrane transport) in bacteria. In Enzymes: Units of Biolcgical Structure and Function, pp. 509-522. Edited by O. H. Gaebler. New York: Academic Press.

Fensom, A. H. \& PiRT, S. J. (1975). Protein turnover measured by ${ }^{18} \mathrm{O}$ exchange with $\mathrm{H}_{2}{ }^{18} \mathrm{O}$ in non-growing cells of Agrobacterium tumefaciens. Journal of General Microbiology 87, 159-162.

Gray, W. J. H. \& Midgley, J. E. M. (1970). The control of ribonucleic acid synthesis in bacteria: steady-state content of messenger ribonucleic acid in Escherichia coli M.R.E. 600. Biochemical Journal 120, 279-288.
Guerrero-Caballero, R. \& Ruiz-Herrera, J. (1971). A kineticanalysis of the citrate permeability. system from Aerobacter aerogenes. Reviews of Latin-American Microbiology 13, 297-302.

HARRISON, D. E. F. (1976). The regulation of respiration rate in growing bacteria. Advances in Microbial Physiology 14, 243-313.

Harrison, D. E. F. \& Loveless, J. E. (1971 a). The effect of growth conditions on respiratory activity and growth efficiency in facultative anaerobes grown in chemostat culture. Journal of General Microbiology 68, 35-43.

HaRRISON, D. E. F. \& Loveless, J. E. (1971b). Transient responses of facultatively anaerobic bacteria growing in chemostat culture to a change from anaerobic to aerobic conditions. Journal of General Microbiology 68, 45-52.

Harrison, D. E. F. \& MaITRA, P. K. (1969). Control of respiration and metabolism in growing Klebsiella aerogenes: the role of adenine nuclectides. Biochemical Journal 112, 647-656.

HARRISON, D. E. F. \& PIRT, S. J. (1967). The in. fluence of dissolved oxygen concentration on the respiration and glucose metabolism of Klebsiella aerogenes during growth. Journal of General Microbiology 46, 193-211.

JACOB, F. \& MONOD, J. (1961). Genetic regulatory 
mechanisms in the synthesis of proteins. Journal of Molecular Biology 3, 318-356.

KoCH, A. L. (1963). The inactivation of the transport mechanism for galactosides of Escherichia coli under various physiological conditions. Annals of the New York Academy of Sciences 102, 602-620.

LAWTHER, R. P. \& COOPER, T. G. (1975). Kinetics of induced and repressed enzyme synthesis in Saccharomyces cerevisiae. Journal of Bacteriology 121, 1064-1073.

MACKeRETH, F. J. H. (1964). An improved galvanic cell for determination of oxygen concentrations in fluids. Journal of Scientific Instruments 41, 38-41.

MANDELSTAM, J. (1960). The intracellular turnover of protein and nucleic acids and its role in biochemical differentiation. Bacteriological Reviews 24, 289-308.

Marr, A. G., Nilson, E. H. \& Clark, D. J. (1963). The maintenance requirement of Escherichia coli. Annals of the New York Academy of Sciences 102, 536-548.

McGinnis, J. F. \& PAIGeN, K. (1969). Catabolite inhibition: a general phenomenon in the control of carbohydrate utilization. Journal of Bacteriology 100, 902-913.

McGinnis, J. F. \& Paigen, K. (1973). Site of catabolite inhibition of carbohydrate metabolism. Journal of Bacteriology 114, 885-887.

Neijssel, O. M. \& Tempest, D. W. (1975). The regulation of carbohydrate metabolism in Klebsiella aerogenes NCTC 418 organisms, growing in chemostat culture. Archives of Microbiology 106, 251-258.

Páca, J. \& Vratislav, G. (1977). Growth and metabolic activity of Klebsiella aerogenes in a chemostat culture. Journal of Fermentation Technology 55, 213-223.

PINE, M. J. (1965). Heterogeneity of protein turnover in Escherichia coli. Biochimica et biophysica acta 104, 439-456.

Pine, M. J. (1970). Steady-state measurement of the turnover of amino acid in the cellular proteins of growing Escherichia coli: existence of two kinetically distinct reactions. Journal of Bacteriology 103, 207-215.

PINE, M. J. (1972). Turnover of intracellular proteins. Annual Review of Microbiology 26, 103-126.

PIRT, S. J. (1975). Principles of Microbe and Cell Cultivation. Oxford: Blackwell Scientific Publications.

PIRT, S. J. \& Righelato, R. C. (1967). Effect of growth rate on the synthesis of penicillin by Penicillium chrysogenum in batch and continuous cultures. Applied Microbiclogy 15, 1284-1290.

Robertson, J. J. \& Halvorson, H. O. (1957). The components of maltozymase in yeast, and their behaviour during deadaptation. Journal of Bacteriology 73, 186-198.

TøNnesen, T. \& Friesen, J. D. (1973). Inhibitors of ribonucleic acid synthesis in Saccharomyces cerevisiae: decay rate of messenger ribonucleic acid. Journal of Bacteriology 115, 889-896.

Villarreal-Moguel, E. I. \& Ruiz-Herrera, J. (1969). Induction and properties of the citrate transport system in Aerobacter aerogenes. Journal of Bacteriology 98, 552-558.

Votruba, J., Sobotka, M. \& Prokop, A. (1977). The effect of air hold-up on readings of dissolved oxygen probes. Biotechnology and Bioengineering 19, 435-438. 